\title{
How to Survey Displaced Workers in Switzerland: Ways of Addressing Sources of Bias
}

\author{
Isabel Baumann, Oliver Lipps, Daniel Oesch, and Caroline Vandenplas
}

\section{Introduction}

Involuntary job loss often comes as a shock for the affected individuals. Dismissal not only hampers individuals' health (Kuhn et al. 2009) and life satisfaction (Oesch and Lipps 2013), but may also negatively affect their occupational trajectory. Displaced workers are deprived of the positive components of work - they lost not only a source of income but also their social contacts, an important determinant of their social status, and the time structure implied by an economic activity (Andersen 2008). Threatened by the risks of financial deprivation and social exclusion, displaced workers are in a state of heightened vulnerability. Yet not all individuals are exposed to these threats to the same extent: some are more disadvantaged than others.

When trying to determine workers' occupational trajectories after job dismissal, researchers face a number of methodological problems. The fact that workers displaced individually are probably a self-selected group of people makes the causal analysis of the impact of job loss on the ensuing work career tricky: the same factor causing the workers to lose their jobs such as poor health or lack of motivation may also reduce their re-employment prospects (Brand 2015).

\section{Baumann $(\bowtie) \cdot$ D. Oesch \\ NCCR LIVES, Lausanne, Switzerland}

Center for Health Sciences, Zurich University of Applied Sciences (ZHAW), Winterthur,

Switzerland

e-mail: isabel.baumann@zhaw.ch

O. Lipps

FORS (Swiss Centre of Expertise in the Social Sciences), Lausanne, Switzerland

C. Vandenplas

FORS (Swiss Centre of Expertise in the Social Sciences), Lausanne, Switzerland

Centre for Sociological Research, Catholic University of Leuven, Leuven, Belgium

(C) The Author(s) 2016

M. Oris et al. (eds.), Surveying Human Vulnerabilities across the Life Course,

Life Course Research and Social Policies 3, DOI 10.1007/978-3-319-24157-9_7 
This chapter discusses some of the problems afflicting the survey-based analysis of how displaced workers overcome the critical event of a job loss and then tries to present a few empirical solutions. A way out is to use plant closure - a reason beyond people's control - as an exogenous instrument for job displacement to tackle the endogeneity problem (Schwerdt et al. 2010).

Since the Swiss Labour Force Survey does not distinguish between different reasons for involuntary job loss, we ran our own survey on workers who lost their job 2 years earlier. The achieved sample consists of around 1200 people - the entire workforce of five Swiss manufacturing plants that had closed down completely after the financial crisis of 2008. The research objective was to identify the workers' reemployment prospects.

The chapter is structured as follows. The first section discusses two types of survey bias: selection bias and nonresponse bias. The second section describes the nuts and bolts of our survey on displaced workers and presents the data. The third section shows the empirical analysis of nonresponse bias in our sample. The fourth section then presents the re-employment rates of displaced workers based on different data subsets. The conclusion sums up the main findings and discusses some challenges faced in the survey process.

\section{Selection and Nonresponse Bias in Survey Studies}

When conducting a survey, researchers must be aware of a set of error sources - an approach summarized in the concept of the total survey error approach - and, more specifically, survey bias (Groves and Lyberg 2010:850). Bias occurs at the variable level when the factors that drive the bias are correlated with the relevant variables (Groves and Peytcheva 2008:169). In the following sections we discuss two types of bias that we consider particularly relevant for our study and briefly address a third one.

\subsection{Selection Bias}

Selection bias emanates from a non-random attribution of individuals into a sample and implies that the selected individuals are not representative of the population. Part of the problem is that one does not know whether such a selection has taken place and if so, which characteristics drove the process (Antonakis et al. 2010). Selection bias implies that the independent variables are endogenous, making causal inference on the basis of these data impossible (Hamilton and Nickerson 2003).

The ideal solution to avoid selection bias would be to run an experiment. Since in the social sciences experiments are often difficult for ethical and practical reasons, other methods for causal inference must be adopted (for an overview, see Angrist and Pischke 2008). A way around experiments is to choose 
natural experiments - events that occur without the contribution of the researcher, where an exogenous source of variation in the social phenomenon of interest randomly determines individuals' assignment to a treatment (Meyer 1995:151).

Plant closure comes close to such a setting: at the individual level, the assignment to the treatment is random because the workers are dismissed independently of their health or work performance. The fact that the entire workforce of a company loses their job suggests that selection into displacement is limited (Eliason and Storrie 2009:1397; Gibbons and Katz 1991:353). Moreover, reverse causality is unlikely in the case of plant closure: if displaced workers are in poor health, it is unlikely that their sickness has caused the plant to close, but rather that plant closure and job loss have negatively affected their health (Kuhn et al. 2009:1099). The advantage of plant closure as an analytical instrument for unemployment thus is that displaced people were not primarily selected into unemployment - that is, dismissed - on the basis of other characteristics such as lack of motivation, poor health or an insubordinate personality. It is thus possible to identify the causal effect of redundancy on workers' ensuing trajectories (Schwerdt et al. 2010:137).

At the same time, this instrument is not immune to two types of selection bias. First, there may be some extent of self-selection of workers into industries and plants that are more vulnerable to economic and structural problems (Cha and Morgan 2010:1141). Evidence from Germany suggests that older workers and workers without technical training or university education are more likely to be made redundant (Burda and Mertens 2001:22-24). Thus, belonging to the workforce of a non-profitable plant is not completely random - confronted with a choice, much sought-after specialists may think twice before seeking employment in a plant that shows evidence of economic difficulties. The same study additionally shows that workers employed in small firms have a higher propensity to be dismissed.

A second selection bias arises from the fact that some workers anticipate the closure of their plant and leave it before the closure is officially announced. If more ambitious or motivated workers select themselves out of the sample, the remaining sample is not representative for the total population. In an Austrian study, Schwerdt (2011:100) shows that early plant leavers tend to have higher re-employment rates and lower earning losses than workers displaced at the very end. According to the author the outcome is due to compositional differences between the two groups in terms of productivity-related characteristics. Turnover before plant closure thus seems to be selective.

\subsection{Nonresponse Bias}

Despite the use of plant closure as a methodological instrument to limit selection bias in the sample to be surveyed, individual differences in survey participation behaviour may still result in a selective sample. If the group of nonrespondents were missing completely at random, this would only reduce the statistical power of results without inducing systematic bias. Unfortunately, nonresponse most often is biased: 
Individuals who are not participating in a survey are likely to be less interested in the topic or to have lower literacy in the questionnaire's language (Groves and Couper 1998; Stoop 2005). It is thus important to understand the mechanism behind nonresponse and, if possible, to correct for it.

Some subgroups may be particularly difficult to observe. For example, it has been shown for Switzerland that individuals with an immigration background from a country where none of the survey languages is spoken are heavily underrepresented in surveys such as the Swiss Household Panel or the Swiss Labour Force Survey (Lipps et al. 2013:248-251; Laganà et al. 2011:2). The participation rate is particularly low among Turks, Ex-Yugoslavians and Albanians. In contrast, Italian, French and German nationals have participation rates similar to that of Swiss nationals.

Conventional efforts to increase the overall response rate such as repeated contact attempts or government survey sponsoring tend to lead to the inclusion of more respondents of the same type instead of accessing subgroups that are traditionally less likely to participate (Laganà et al. 2011:22; Groves and Peytcheva 2008:176). These methods thus seem to increase the under-representation of minorities with immigrant backgrounds. While a high participation rate leads to more robust estimates, the increase in the response rate does not guarantee the sample's representativeness (Groves and Peytcheva 2008:168). Therefore, the objective of increasing the response rate should always be coupled with an effort to reduce bias by obtaining answers from under-represented subgroups (Luiten and Schouten 2013). In order to reach individuals belonging to subgroups with traditionally low participation rates, a more effective solution is to alter the survey protocol, for instance through a shorter questionnaire - a practice often applied in nonrespondent follow-up surveys (Peytchev et al. 2009:786; Lynn 2003).

A second possibility to reduce nonresponse bias is to use financial incentives. Incentives have proven successful at pulling in those respondents who otherwise would not answer the questionnaire (Dillman et al. 2009:249). They encourage respondents to reciprocate by completing the survey (Dillman et al. 2009:238). According to the economic exchange theory, the amount of the incentive should compensate the respondents for the opportunity costs of the time invested to participate in the survey (Citro 2010:73). Research in survey methodology indicates that unconditional and cash incentives are more effective than incentives contingent on completing a survey (Harrison 2010:519; Lipps 2010:84). Incentives are particularly important in written or online surveys where there is no interviewer to motivate and support the participants (Mehlkop and Becker 2007:8).

A third possible solution for addressing nonresponse bias consists in mixing survey modes. Mixed-mode approaches using combinations of face-to-face, telephone, internet and paper-pencil questionnaires tend to be more effective at enhancing representativeness than single-mode surveys: different modes usually help to activate different subgroups of the surveyed sample (Dillman et al. 2009; Hayashi 2007). However, taken on their own, every single survey mode has its downside: internet coverage is still limited, notably among older people; landline telephone coverage has decreased in recent years; mail surveys are known to have a comparably high 
nonresponse rate; and face-to-face interviews are resource intensive (Schräpler 2001:13; Kempf and Remington 2007; Ernst Stähli 2012; Lipps and Kissau 2012). While the combination of different modes may help to increase representativeness, its drawback is an incomparable measurement error across modes (Dillman and Messer 2010:551-553; Vannieuwenhuyze and Loosveldt 2013).

A last possibility to deal with nonresponse bias is to adopt postsurvey adjustments by means of weighting. The idea is to give underrepresented groups a higher weight than overrepresented groups (Little and Vartivarian 2005). The quality of the weights depends on the available data: if the socio-demographic variables used to construct the weights do not affect the phenomenon of interest, the adjustments weights will not correct for nonresponse bias (Groves and Peytcheva 2008).

Finally, a third source of bias needs to be briefly discussed: measurement error. This source of bias typically arises if the questionnaire is poorly designed: ambiguous questions, confusing instructions, and easily misunderstood terms are examples of questionnaire problems that lead to measurement error (Biemer 2010:32). A technique to reduce measurement error is to validate survey answers by means of external data sources. For instance, the combination of survey data with register data allows controlling for the accuracy of the survey data (Sakshaug et al. 2012:536). Yet obtaining register data is often challenging because of data protection legislation, matching problems, and the need of informed consent by the concerned individuals.

\section{Survey Procedure and Data}

\subsection{Sampling Strategy}

In autumn 2011, we conducted our survey on the workforce of five companies in Switzerland's manufacturing sector that closed down in 2009 or 2010 . The objective was to examine the re-employment prospects of displaced industrial workers about 2 years after their dismissal. In this section, we briefly present the nuts and bolts of our survey.

To begin with, the selection of companies was based on the following four criteria. First, we limited our sample to workers from production sites that closed down completely. As discussed earlier, this is relevant because plants that dismiss only parts of their workforce are likely to hold on to their most valuable workers, while making those with lower work performance redundant - which would result in a selective sample of workers. Second, we chose plants that closed down about 2 years before the survey. We thus try to capture long-term unemployment and, more specifically, the crucial moment when the unemployed exhaust their right to draw unemployment benefits. This happens in Switzerland - depending on the workers' age and duration of contribution - after 1-2 years of entitlement. Third, we selected plants that employed, at the moment of closure, no less than 150 employees. In order to limit time costs, we focused on mid-sized and large plants. Fourth, we focused 
Table 1 Information on the five manufacturing plants included in the survey

\begin{tabular}{l|l|l|l}
\hline Plant & Sector & Workers displaced & Displacement dates \\
\hline Plant A & Metal and plastic products & 204 & September 2009 to March 2010 \\
\hline Plant B & Metal products & 169 & January 2010 \\
\hline Plant C & Printing & 262 & December 2009 \\
\hline Plant D & Chemicals & 430 & January 2009 \\
\hline Plant E & Machinery & 324 & October 2009 to August 2010 \\
\hline Total workers displaced & 1389 & \\
\hline Refusal and invalid addresses & 186 & \\
\hline Eligible sample & 1203 & \\
\hline
\end{tabular}

on manufacturing - the sector most strongly affected by job displacement. These criteria helped us to reach a critical mass of workers with a small number of plants.

Through media screening and contact with the cantonal employment offices, we made an inventory of plants that corresponded to these four criteria and identified ten plants. This inventory constitutes our sampling frame. We then contacted all these plants by mail and telephone, succeeding in convincing five plants to participate in the survey. The five missing plants are similar to the participating firms in terms of size, sector, displacement date and geographic location. Table 1 gives an overview over the surveyed plants and shows that they had been active in the sectors of metal and plastic production, printing, chemicals or machinery, employed between 169 and 430 workers at the moment of closure and closed down between January 2009 and August 2010.

For two plants we accessed the workers through the company's management, for one plant through the works council and for two plants through the cantonal employment offices. For data protection reasons, we had to obtain the workers' consent to use their addresses. Workers thus received a letter informing them about our study and the intention of the address providers - company management, work council, or employment office - to give us access to their postal addresses. For practical reasons, the workers only had to react in case of refusal.

Table 1 shows that 186 or $15 \%$ of all displaced workers either had invalid addresses (because they moved or - in a few cases - were deceased) or refused access. The main reasons for refusals were (a) that workers did not feel concerned by our study, (b) that workers did not speak the survey languages (French and German), and (c) that some individuals were frustrated by their occupational situation. After all, a non-negligible share of our original sample dropped out and the surveyed sample resulted in 1203 individuals.

Since we selected those units easiest to be surveyed (that is, those companies agreeing to participate), our sampling strategy at the level of companies provides us with a convenience sample (Lohr 1999:5). Convenience sampling implies that the data are not generated by a known probability mechanism such as random sampling - and hence does not allow for inferring from the sample to the whole 
population (Western and Jackman 1994:412; Berk 2004:51). A conservative interpretation would thus be that our findings need to be read as the results of a case study.

\subsection{Data Collection}

Our data collection instrument was a questionnaire with about 60 mainly closedended questions. Many of the questions were adopted from established surveys such as the Swiss Household Panel or the Swiss Labour Force Survey. Since the target group consists in individuals living in both, the German- and French-speaking regions of Switzerland, the questionnaire was fielded in two languages. It was first cross-examined by survey experts and then completed by and discussed with four workers of the survey population. The questionnaire was both printed on paper and provided online. Furthermore some workers answered by telephone; they had the possibility to answer only to a sub-selection of the questions. We hence conducted a mixed-mode survey where questionnaires were mainly self-administered.

We started the survey at the end of September 2011 by sending out an advance letter. The aim of this letter was to describe the purpose of our study and to announce the arrival of the questionnaire. The letter contained the URL to the online questionnaire that allowed workers to start participating right away. A recommendation letter by the Swiss State Secretariat of Economic Affairs (SECO) whose purpose was to enhance the survey's legitimacy by showing governmental support - accompanied the advance letter. One week later, at the beginning of October, workers received the paper and pencil version of the questionnaire for the first time, including a pre-stamped return envelope. This mailing was accompanied by an unconditional financial incentive in the form of a voucher worth ten Swiss Francs for Switzerland's biggest retail trade company. About 1 month later, at the beginning of November, workers who had not yet participated received the paper and pencil questionnaire for a second time.

A crude analysis of response rates by a national origin proxy suggested that immigrants tended to be under-represented in our study. Since we did not have information for all workers about their nationality, the proxy for national origin was created on the basis of workers' family names. Thereby, we distinguished four groups: (1) Switzerland, France and Germany, (2) Spain and Portugal, (3) Italy, and (4) other countries, notably Ex-Yugoslavia and Turkey. Group (1) represents $71 \%$ of the workers, group (2) $3 \%$, group (3) $8 \%$ and group (4) $17 \%$. When checking the response rates across these four proxy groups - an admittedly rough indicator for immigration background - we found the expected differences: group (1) had a response rate of $66 \%$, group (2) of $56 \%$, group (3) of $55 \%$ and group (4) of $40 \%$. To increase the response rate of group (4), we drew a random sample of nonrespondents in this group and succeeded, in December, to conduct 15 telephone interviews with workers with an Ex-Yugoslavian or Turkish origin. This measure led to a final response rate of group (4) of $52 \%$ - a response rate similar to that of the proxy groups (2) and (3). 
The overall response rate for the survey was $62 \%$ and the responding sample included 748 workers. The properties of our responding sample are shown in Table 5 in the appendix. $83 \%$ of the workers in our survey were male, the mean age was 47.3 years, $57 \%$ had an upper secondary education (apprenticeship) and $55 \%$ were employed as craft workers, machine operators or workers in elementary jobs (henceforth: production workers).

\subsection{Combining Survey Data with Plant and Register Data}

A potential problem of our mixed-mode survey is differential measurement error. We tried to address this bias by linking our survey data with data from the firms and with administrative data from the unemployment register. The advantage of the data from the companies is that it is available for all workers. This allows us to examine whether respondents are representative for the surveyed sample. However, the same variables were not available for all plants: while we received important information such as occupation or age for workers in some plants, we only obtained information on the displacement date for other plants.

The administrative data stems from the AVAM/PLASTA ${ }^{1}$ database of the public unemployment insurance. Access was subject to two conditions: first, we could only obtain information on those displaced workers who did not refuse access. ${ }^{2}$ This implies that both, survey respondents who did not refuse access and all survey nonrespondents (who, by definition, did not refuse since refusing implied to tick a box in the questionnaire) were covered by this data source. Second, workers needed to be identifiable in the unemployment insurance database on the basis of their name and address - which was not possible for everybody, because not all the displaced workers were enrolled in the unemployment insurance: some had found a job right away, others went into early retirement, and a third group may have preferred to avoid the stigma of living from unemployment benefits. Moreover, some workers' address could not be tracked since it had changed.

At the end, it was possible to identify 355 workers in the database of the unemployment insurance, 165 of whom did not participate in the survey. Combining survey and register data we thus have information on 913 workers or $76 \%$ of the total surveyed sample. For the post-displacement occupational situation - our central dependent variable - we have employment status for 884 workers (74\% of the total surveyed sample).

\footnotetext{
${ }^{1}$ Informationssystem für die Arbeitsvermittlung und Arbeitsmarktstatistik/Système d'information en matière de placement et de statistique du marché du travail.

${ }^{2}$ In order to receive the worker's agreement we included a question in the questionnaire which was formulated in a way that the respondents had to inform us if they did not wish us to access their data. Only 144 workers - corresponding to $19 \%$ of the respondents and $12 \%$ of the survey population - refused access.
} 


\section{Survey Participation}

As mentioned, the overall response rate in our survey was $62 \%$. This comparatively high response rate is probably due to the features of our survey design: multiple contact attempts, mixing modes, unconditional financial incentives and an official recommendation letter by the SECO. In addition, the focus on specific populations may also result in higher response rates because respondents feel concerned by the survey topic and are interested in the goals of the study (Sweet and Moen 2011:9). Comments that we received with the questionnaires suggest that the displaced workers were happy to be able to communicate about their experiences after plant closure.

However, the crucial question is not whether the response rate is high or low, but whether different worker subgroups had a similar propensity to participate in the survey. First, we examine this question by analysing the response rate for different worker subgroups, relying on firm data that is available for both respondents and nonrespondents. Second, we analyse whether the groups of respondents and nonrespondents are different in terms of socio-demographic characteristics by relying on register and survey data.

Table 2 presents the response rates by plant, sex and occupation in the predisplacement job. Since the latter two variables are available only for three firms, the number of observations for former occupation and sex is smaller than for the survey population $(\mathrm{N}=1203)$. The response rates do not vary much across plants, ranging from 55 to $66 \%$. Large response rate differences according to company could be problematic if the firms had very different characteristics and would differ in the labour market prospects of their workforces. Yet since we are not confronted with large differences, this issue is not relevant here. What we know is that there does not seem to be a relationship between the number of months since plant closure and

Table 2 Response rate according to plant, former occupation and sex

\begin{tabular}{|c|c|c|c|}
\hline & Characteristics & Response rate $(\%)$ & $\mathrm{N}$ \\
\hline \multirow[t]{5}{*}{ By plant } & Plant A (19-24 months since closure) & 55 & 183 \\
\hline & Plant B (21 months since closure) & 61 & 147 \\
\hline & Plant C (22 months since closure) & 62 & 228 \\
\hline & Plant D (33 months since closure) & 63 & 357 \\
\hline & Plant E (13-24 months since closure) & 66 & 288 \\
\hline \multirow{6}{*}{ By former occupation } & Machine operators and elementary occupations & 60 & 185 \\
\hline & Clerks & 62 & 29 \\
\hline & Craft and trade workers & 66 & 145 \\
\hline & Technicians and associate professionals & 69 & 126 \\
\hline & Managers & 75 & 62 \\
\hline & Professionals & 81 & 32 \\
\hline \multirow[t]{2}{*}{ By sex } & Men & 59 & 630 \\
\hline & Women & 69 & 130 \\
\hline
\end{tabular}


the response rate: the response rate in plant $\mathrm{D}$, having closed 33 months prior to the survey, is very similar to that of plant B and plant C, which closed 21 or 22 months prior to the survey (63\% as compared to 61 and $62 \%$ ).

Table 2 shows greater differences in response rates with respect to the former occupation. Not surprisingly, we find that machine operators and workers in elementary occupations have the lowest response rate, whereas professionals and managers have the highest. While four out of five professionals participated in our survey, only three out of five machine operators did so. We expected clerks to stand out in comparison with production workers since the former are more used to filling in forms than their colleagues in manual occupations. Contrary to our expectations, however, we found that the response rates between clerks on the one hand and craft workers and machine operators on the other hand do not vary much, ranging between 60 and $66 \%$. Finally, the response rates with respect to sex confirm prior findings in survey research that women are more likely to participate in surveys than men (Voorpostel 2010:367). We find that only 59\% of the men, but $69 \%$ of the women responded to our questionnaire.

In the next section we compare a series of socio-demographic characteristics between respondents and nonrespondents (Table 3). While for the respondents register and survey data is available, for the nonrespondents we only rely on register data. If we compare the respondents (all) and the nonrespondents (UEI register) we can see that the respondents are on average substantially older, more highly educated and were less often employed as production workers.

By comparing the profile of respondents for each survey mode in terms of age, education and occupation, we get an idea about how different modes affect the socio-demographic composition of our sample. Twenty-one percent of all respondents completed the questionnaire online, $76 \%$ used the paper and pencil questionnaire, and $3 \%$ answered by telephone. It is not surprising that paper and

Table 3 Respondents characteristics by survey mode and unemployment insurance register status

\begin{tabular}{l|l|l|l|l}
\hline Response and mode & $\mathrm{N}$ & $\begin{array}{l}\text { Mean age at } \\
\text { displacement } \\
\text { (in years) }\end{array}$ & $\begin{array}{l}\text { Share of less } \\
\text { educated } \\
\text { (in \%) }\end{array}$ & $\begin{array}{l}\text { Share of } \\
\text { production } \\
\text { workers (in \%) }\end{array}$ \\
\hline Respondents - all & $\underline{748}$ & $\underline{47.3}$ & $\underline{14}$ & $\underline{55}$ \\
\hline Internet & 157 & 45.5 & 8 & 40 \\
\hline Paper and pencil, 1st mailing & 398 & 47.7 & 15 & 57 \\
\hline Paper and pencil, 2nd mailing & 165 & 48.3 & 13 & 62 \\
\hline Telephone interviews & 22 & 43.4 & 38 & 85 \\
\hline Respondents - UEI register & 190 & 48.5 & 13 & 59 \\
\hline Respondents - not in UEI register & 558 & 46.8 & 14 & 54 \\
\hline Nonrespondents - all & 455 & - & - & - \\
\hline Nonrespondents - UEI register & $\underline{165}$ & 41.6 & $\underline{36}$ & $\underline{69}$ \\
\hline
\end{tabular}

UEI stands for unemployment insurance. The less-educated include individuals with less than upper secondary education. Production workers include individuals who were employed before displacement in the International Standard Classification of Occupations (ISCO) groups 7, 8 or 9 
pencil was clearly the most frequently used mode since we had workers' postal address, but not their e-mail address. Participants who answered on Internet are somewhat younger, more likely to be better educated and less likely to have worked in a production job compared with participants having answered the questionnaire on paper. Furthermore workers who responded by the paper and pencil questionnaire after the first mailing are similar to those who answered by means of the same mode after the second mailing. Differences between respondents using Internet as compared to paper and pencil are somewhat larger, but still not very substantial. In contrast, differences are noteworthy with respect to respondents who had answered the questionnaire by telephone: this specifically targeted group is younger, more likely to be lower educated and to have worked in a production job as compared to respondents who answered the survey by other means.

The strategy of mixing modes and multiple contact attempts seems to have paid off in terms of a higher response rate. The modes partially coincided with different moments of contact. The first contact gave participants access to the online questionnaire. The first survey participants therefore responded by Internet; yet the online questionnaire was open throughout the entire survey. The second and third contact allowed workers to fill in the paper and pencil questionnaire. The fourth contact by telephone concerned exclusively a small subsample. However, some additional workers who did not belong to this subsample contacted us via telephone and answered the survey by this means. Our results reveal that the second mailing of the paper questionnaire to nonrespondents brought in more people who are much like those respondents who already answered by paper and pencil after the first mailing. By reminding people to participate, the second mailing was effective in increasing the response rate by 14 percentage points. However, unlike the telephone interview, it does not seem to have done much to improve the sample's representativeness.

Participants who responded by telephone seem to be much more similar to nonrespondents than respondents using the two dominant modes (paper and pencil and Internet). The difference is particularly marked with respect to education: while $36 \%$ of the nonrespondents have not obtained upper secondary education, this is the case for only $8 \%$ of Internet respondents and for $14 \%$ of paper and pencil respondents. Among the telephone respondents in contrast, the share of workers with a lower level of education is even higher than among nonrespondents (38\%). This finding suggests that telephone interviews were effective in motivating workers who, otherwise, would not have participated in the survey.

Table 3 also shows us that, overall, participants who registered in the unemployment insurance are similar to those who did not register: while the former are somewhat older and more likely to have worked as production workers, the share of low-educated workers is almost identical. In contrast, the small group of workers who registered in the unemployment insurance and who did not respond to our survey present a very different profile than respondents: on average, they are much younger and those with a lower level of education, as well as production workers, make up a much larger share. Clearly, having access to register data provides us with observations for potentially more disadvantaged workers. 
Table 4 Variables taken from plant register data to construct nonresponse adjustment weights

\begin{tabular}{l|l|l|l|l|l|l}
\hline & Displacement date & Sex & Occupation & Age & Nationality & Country of residence \\
\hline Plant A & $\mathrm{x}$ & & & & & $\mathrm{x}$ \\
\hline Plant B & & $\mathrm{x}$ & & & & \\
\hline Plant C & & $\mathrm{x}$ & $\mathrm{x}$ & $\mathrm{x}$ & & \\
\hline Plant D & & & $\mathrm{x}$ & & $\mathrm{x}$ & \\
\hline Plant E & & $\mathrm{x}$ & & & & \\
\hline
\end{tabular}

The difference in the subgroups' characteristics suggests that we are possibly still confronted with nonresponse bias. A relatively simple method to correct for this problem is unit nonresponse adjustment weighting. Accordingly, we use a technique that is based on a missing at random (MAR) assumption. This means that subgroups based on variables available for respondents and nonrespondents are created, with the assumption that non-participation happened at random within these subgroups. This method is often used in nonresponse adjustment (Little 1986) and consists in adjusting each subgroup separately for nonresponse.

Since for every plant in our sample, other variables are available, we used different variables for each plant when constructing the individual-level weights. The variables used for nonresponse adjustment depending on the plant are shown in Table 4. This type of nonresponse adjustment is most effective when the available variables used to construct the subgroups (sex, occupation, age, nationality) correlate with the variable of interest in the study (re-employment). The literature suggests that this is the case: sex, occupation, age, and nationality affect reemployment chances (e.g. Fallick 1996; Kletzer 2001; Jolkkonen et al. 2012). However, it might be problematic to construct adjustment weights on the basis of different variables. Yet since no variable is available for all firms, we assume that our construction is still better than no weighting at all. How these weights change our results in terms of reemployment rates will be shown in the next section.

\section{Re-employment Rates of Different Subsets}

The crucial question is whether nonresponse, different survey modes and weighting lead us to draw different conclusions as to the re-employment prospects of displaced workers. Figure 1 answers this question by showing workers' occupational status about 2 years after displacement for different data subsets. If we use the survey data for all workers (1) we find that $67.9 \%$ of the workers are re-employed. $15.9 \%$ are still unemployed, $13.1 \%$ are retired and the remaining $3.1 \%$ exited the labour market for training, childcare or due to disability. If we consider the weighted survey data (2), the re-employment rate is $68.7 \%$ - slightly higher than for the unweighted survey data. The nonresponse adjustment weight thus does not 


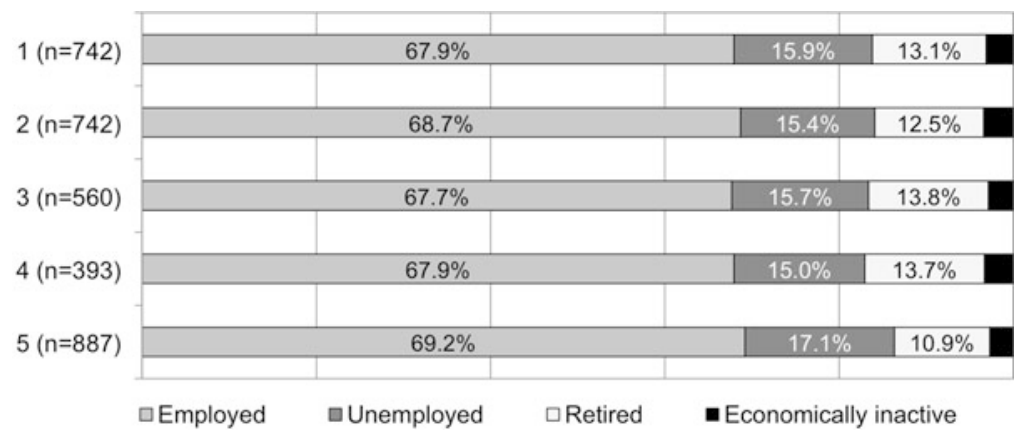

Fig. 1 Employment status of workers about 2 years after displacement by different data subsets. Note: 1 Survey data (for all workers), 2 Survey data (for all workers) - weighted, 3 Survey data for workers responding by paper and pencil questionnaire, 4 Survey data for workers responding before second mailing of the questionnaire, 5 Survey data (for all workers) combined with register data

seem to have a substantial effect on the result. We would have expected a lower reemployment rate for the weighted than the unweighted data as the characteristics of nonrespondents typically do not favour re-employment. This implies that - with respect to the weighting variables - the group of respondents is similar to the group of non-respondents in terms of re-employment. Yet the weighting induces a slightly lower rate of retired workers. This suggests that the retired are slightly overrepresented among the survey respondents. As a matter of fact, Table 3 above suggests that respondents are on average several years older than nonrespondents.

If we use survey data for workers who responded by paper and pencil (3), the reemployment rate amounts to $67.7 \%$. If we use survey data of workers who responded before the second mailing of the questionnaire (4), the re-employment rate is $67.9 \%$. These results are basically the same as those for survey data for all workers (1) and suggest that the re-employment prospects of those workers who responded to the survey through the paper and pencil questionnaire or before the second mailing are very similar to the whole group of survey respondents.

Finally, if we combine the survey data with register data (5), the share of workers who have found a new job increases to $69.2 \%$. Similarly, the unemployment rate is higher if we base our analysis on this subset of data. This is not surprising since our unemployment register data does not include workers who went into (early) retirement or exited the labour market for other reasons. In contrast, it is remarkable that the unemployment rate is not higher than $17.1 \%$ : the socio-demographic characteristics of the nonrespondents (see Table 3) might have suggested that they are substantially more likely to be unemployed than the respondents.

If we compare our results for re-employment rates after plant closure with other studies, the outcomes are similar. In a recent study focusing on six industrial Swiss companies, the author finds re-employment rates of between 72 and $92 \%$ and unemployment rates between 8 and $28 \%$ (Wyss 2009:27). Yet this result does not 
consider the share of workers who quit the labour market because of retirement or training. If we adopt the same approach as Wyss (2009), we find a re-employment rate of $80 \%$ and an unemployment rate of $20 \%$.

Likewise, a study on plant closure in Finland highlights that 1 year after displacement $62 \%$ of the workers were re-employed, $14 \%$ were unemployed, $19 \%$ were in education or training and $5 \%$ had dropped out of the labour force (Jolkkonen et al. 2012:88). While the re-employment and unemployment rate in the Finnish study are slightly lower than in our case, a much higher share of workers was in education or training, probably organized within the unemployment institution. Similarly, a thorough analysis of the American Displaced Worker Surveys 1984-2000 finds the reemployment rate for displaced mid-age, mid-educated male manufacturing workers in the United States to be $62 \%$ in the early 1990s (Kletzer 2001:45). These comparisons provide some evidence that the findings from our survey also apply to other countries. Yet since the reported studies are set at different moments in the business cycles and in countries with a different labour market structure, we should not make too much of the similarities between these studies and our results.

\section{Conclusion}

Our survey on displaced manufacturing workers in Switzerland strives at understanding occupational trajectories after job loss. Based on a mixed-mode questionnaire, we surveyed about 1200 workers who lost their job after a financial crisis. The collected data were matched with firm data and register data from the unemployment insurance in order to obtain information about nonrespondents. When conducting this survey, we were confronted with two main problems likely to threaten the quality of the collected data: selection bias, referring to the problem that individuals are non-randomly selected into the sample, and nonresponse bias, referring to the problem that survey respondents and nonrespondents differ in characteristics (e.g. age or education) that are relevant for the outcome.

In this chapter, we have presented possible solutions to deal with survey bias and have evaluated whether these techniques were successful. Selection bias was addressed by using plant closure as an instrument. If a production site closes down completely, it is likely that workers did not lose their job because of poor performance and thus did not self-select into job displacement. Selection of workers into closing firms may not be a major problem in our case since we studied workers from mid-sized and large plants that are less likely to close down. The experiment-like setting of plant closure allows us to study the net effect of workers' socio-demographic characteristics on their re-employment prospects. We dealt with the problem of nonresponse bias by using financial incentives, mixedmode, telephone interviews with national minorities, the inclusion of unemployment register data and weighting.

Although we cannot completely exclude selection and nonresponse bias, our adjustments seem to have reduced them. Our analyses suggest that some methods 
such as repeated contact attempts to reach the surveyed sample increased the response rate but did not reduce nonresponse bias. In contrast, telephone interviews helped to substantially improve the participation of typically underrepresented subgroups. Still, the survey respondents differ from nonrespondents in terms of age, education and occupation: the nonrespondents are on average substantially younger, more often with a lower level of education, and more likely to have worked in production jobs than the respondents. But interestingly these differences have no significant impact on the substantial conclusion about displaced workers' re-employment prospects. When we compare the re-employment rate based on weighted data with the re-employment rate based on data that combine survey and register data, the differences are marginal. One reason might be that the weights did not include variables that are relevant for the substantive variable. Another reason could probably be that those characteristics favouring participation in our survey - age and education - have contradictory effects on re-employment chances. While higher levels of education lead to both higher survey participation and reemployment rates, the opposite mechanism is true for age. Age increases survey participation, but strongly hampers job prospects - notably for workers aged 55 and more (Oesch and Baumann 2015).

Finally, we conclude by highlighting three challenges we faced when conducting the survey. The first challenge was the difficulty to convince companies and plants to participate in the survey since mass displacement implies negative publicity for a company, particularly if workers who were made redundant have not found new employment. A second challenge was the time-consuming construction of the questionnaire, made worse by the need to translate questions and to check its validity in both languages. A third challenge was the, ultimately unsuccessful, attempt to use an optical reading program to automatically input the responses of the questionnaires into a data file.

In contrast, particularly helpful for the survey process was the support provided by the Swiss State Secretariat of Economic Affairs. A first recommendation letter facilitated the contact with companies and employment offices. Once we had access to addresses, the external funding enabled us to provide financial incentives to respondents. The effect of a second recommendation letter that we added to the questionnaire is open: we do not know whether this letter incited - because of the official appearance of the survey - or discouraged - because of potentially negative resentment towards governmental actors - workers to participate in the survey. Our only indicator is the high participation rate, which rather points to a positive effect of the letter. Finally, collaboration with the government facilitated access to the unemployment register data, which proved to be extremely useful in the analyses of nonresponse bias presented here.

Open Access This chapter is licensed under the terms of the Creative Commons AttributionNonCommercial 2.5 International License (http://creativecommons.org/licenses/by-nc/2.5/), which permits any noncommercial use, sharing, adaptation, distribution and reproduction in any medium or format, as long as you give appropriate credit to the original author(s) and the source, provide a link to the Creative Commons license and indicate if changes were made. 
The images or other third party material in this chapter are included in the chapter's Creative Commons license, unless indicated otherwise in a credit line to the material. If material is not included in the chapter's Creative Commons license and your intended use is not permitted by statutory regulation or exceeds the permitted use, you will need to obtain permission directly from the copyright holder.

\section{Appendix}

Table A.1 Descriptive statistics of the responding sample

\begin{tabular}{|c|c|c|}
\hline Variable & & Share in \% \\
\hline \multirow[t]{2}{*}{ Sex } & Men & 83 \\
\hline & Women & 17 \\
\hline \multirow[t]{3}{*}{ Education } & Less than upper secondary education & 14 \\
\hline & Upper secondary education & 57 \\
\hline & Tertiary education & 29 \\
\hline Mean age (in years) & & 47.3 \\
\hline \multirow[t]{5}{*}{ Age (in categories) } & $16-29$ years & 10 \\
\hline & $30-39$ years & 14 \\
\hline & $40-49$ years & 28 \\
\hline & $50-59$ years & 28 \\
\hline & $60-65$ years & 19 \\
\hline \multirow[t]{7}{*}{ Occupation } & Managers (1-digit ISCO 1) & 9 \\
\hline & Professionals (1-digit ISCO 2) & 6 \\
\hline & Technicians (1-digit ISCO 3) & 20 \\
\hline & Clerks (1-digit ISCO 4) & 9 \\
\hline & Craft workers (1-digit ISCO 7) & 27 \\
\hline & Machine operators (1-digit ISCO 8) & 25 \\
\hline & Elementary jobs (1-digit ISCO 9) & 3 \\
\hline \multirow[t]{5}{*}{ Plant } & A (Bern-Mittelland) & 15 \\
\hline & B (Geneva) & 12 \\
\hline & C (Bern-Mittelland) & 19 \\
\hline & D (Bern-Mittelland) & 30 \\
\hline & E (Bern-Mittelland) & 24 \\
\hline
\end{tabular}

Each subgroup sums up to $100 \%$. As an example, $83 \%$ of the workers are men and $17 \%$ are women

\section{References}

Andersen, S. H. (2008). The short- and long-term effects of government training on subjective well-being. European Sociological Review, 24(4), 451-462. doi:10.1093/esr/jen005. 
Angrist, J. D., \& Pischke, J.-S. (2008). Mostly harmless econometrics. An empiricist's companion. Princeton: University Press.

Antonakis, J., Bendahan, S., Jacquart, P., \& Lalive, R. (2010). On making causal claims: A review and recommendations. The Leadership Quarterly, 21(6), 1086-1120. doi:10.1016/j.leaqua.2010.10.010.

Berk, R. A. (2004). Regression analysis. A constructive critique. London: Sage Publications.

Biemer, P. P. (2010). Overview of design issues: Total survey error. In P. V. Marsden \& J. D. Wright (Eds.), Handbook of survey research (pp. 83-137). Bingeley: Emerald.

Brand, J. E. (2015, forthcoming). The far-reaching impact of job loss and unemployment. The Annual Review of Sociology, 41, 1-36.

Burda, M. C., \& Mertens, A. (2001). Estimating wage losses of displaced workers in Germany. Labour Economics, 8(1), 15-41. doi:10.1016/S0927-5371(00)00022-1.

Cha, Y., \& Morgan, S. L. (2010). Structural earnings losses and between-industry mobility of displaced workers, 2003-2008. Social Science Research, 39(6), 1137-1152. doi:10.1016/j.ssresearch.2010.08.002.

Citro, C. F. (2010). Legal and human subjects consideration in surveys. In P. V. Marsden \& J. D. Wright (Eds.), Handbook of survey research (pp. 59-79). Bingeley: Emerald.

Dillman, D. A., \& Messer, B. L. (2010). Mixed-mode surveys. In P. V. Marsden \& J. D. Wright (Eds.), Handbook of survey research (pp. 551-574). Bingeley: Emerald.

Dillman, D., Smyth, L., \& Leani, C. (2009). Internet, mail, and mixed-mode surveys: The tailored design method. Bingeley: Emerald.

Eliason, M., \& Storrie, D. (2009). Job loss is bad for your health - Swedish evidence on causespecific hospitalization following involuntary job loss. Social Science \& Medicine, 68(8), 13961406. doi:10.1016/j.socscimed.2009.01.021.

Ernst Stähli, M. (2012). Switzerland. In S. Häder, M. Häder, \& M. Kühne (Eds.), Telephone surveys in Europe. Research and practice (pp. 25-36). Berlin: Springer.

Fallick, B. C. (1996). A review of the recent empirical literature on displaced workers. Industrial and Labor Relations Review, 50(1), 5-16. doi:10.2307/2524386.

Gibbons, R., \& Katz, L. F. (1991). Layoffs and lemons. Journal of Labor Economics, 9(4), 351380.

Groves, R. M., \& Couper, M. (1998). Nonresponse in household interview survey. New York: Wiley.

Groves, R. M., \& Lyberg, L. (2010). Total survey error: Past, present, and future. Public Opinion Quarterly, 74(5), 849-879. doi:10.1093/poq/nfq065.

Groves, R. M., \& Peytcheva, E. (2008). The impact of nonresponse rates on nonresponse bias: A meta-analysis. Public Opinion Quarterly, 72(2), 167-189. doi:10.1093/poq/nfn011.

Hamilton, B. H., \& Nickerson, J. A. (2003). Correcting for endogeneity in strategic manamagement research. Strategic Organization, 1(1), 51-78.

Harrison, C. H. (2010). Mail survey and paper questionnaires. In P. V. Marsden \& J. D. Wright (Eds.), Handbook of survey research (pp. 499-526). Bingeley: Emerald.

Hayashi, T. (2007). The possibility of mixed-mode surveys in sociological studies. International Journal of Japanese Sociology, 16, 51-63.

Jolkkonen, A., Koistinen, P., \& Kurvinen, A. (2012). Reemployment of displaced workers - The case of a plant closing on a remote region in Finland. Nordic Journal of Working Life Studies, 2(1), 81-100.

Kempf, A. M., \& Remington, P. L. (2007). New challenges for telephone survey research in the twenty-first century. Annual Review of Public Health, 28, 113-126. doi:10.1146/annurev.publhealth.28.021406.144059.

Kletzer, L. (2001). Job loss from imports: Measuring the costs. Washington, DC: Institute for International Economics.

Kuhn, A., Lalive, R., \& Zweimüller, J. (2009). The public health costs of job loss. Journal of Health Economics, 28, 1099-1115. doi:10.1016/j.jhealeco.2009.09.004. 
Laganà, F., Elcheroth, G., Penic, S., Kleiner, B., \& Fasel, N. (2011). National minorities and their representation in social surveys: Which practices make a difference? Quality and Quantity. doi:10.1007/s11135-011-9591-1.

Lipps, O. (2010). Effects of different incentives on attrition and fieldwork effort in telephone household panel surveys. Survey Research Methods, 4(2), 81-90.

Lipps, O., \& Kissau, K. (2012). Nonresponse in an individual register sample telephone survey in Lucerne (Switzerland). In S. Häder, M. Häder, \& M. Kühne (Eds.), Telephone surveys in Europe. Research and practice (pp. 187-208). Berlin: Springer.

Lipps, O., Laganà, F., Pollien, A., \& Gianettoni, L. (2013). Under-representation of foreign minorities in cross-sectional and longitudinal surveys in Switzerland. In J. Font \& M. Méndez (Eds.), Surveying ethnic minorities and immigrant populations: Methodological challenges and research strategies (pp. 241-267). Amsterdam: University Press.

Little, R. J. (1986). Survey nonresponse adjustments for estimates of means. International Statistical Review, 54(2), 139-157.

Little, R. J., \& Vartivarian, S. L. (2005). Does weighting for nonresponse increase the variance of survey means? Survey Methodology, 31(2), 161-168.

Lohr, S. L. (1999). Sampling: Design and analysis. Pacific Grove: Duxbury Press.

Luiten, A., \& Schouten, B. (2013). Tailored fieldwork design to increase representative household survey response rate: An experiment in the Survey of Consumer Satisfaction. Journal of the Royal Statistical Society A, 176(1), 169-189.

Lynn, P. (2003). PEDASKI: Methodology for collection about survey non-respondents. Quality \& Quantity, 37, 239-261.

Mehlkop, G., \& Becker, R. (2007). The effects of monetary incentives on the response rate in mail surveys on selfreported criminal behavior. Methoden - Daten - Analysen, 1(1), 5-24.

Meyer, B. D. (1995). Natural and quasi-experiments in economics. Journal of Business \& Economic Statistics, 13(2), 151-161.

Oesch, D., \& Baumann, I. (2015). Smooth transition or permanent exit? Evidence on job prospects of displaced industrial workers. Socio-Economic Review, 13(1), 101-123. doi:10.1093/ser/mwu023.

Oesch, D., \& Lipps, O. (2013). Does unemployment hurt less if there is more of it around? A panel analysis of life satisfaction in Germany and Switzerland. European Sociological Review, 29(5), 955-967. doi:10.1093/esr/jcs071.

Peytchev, A., Baxter, R. K., \& Carley-Baxter, L. R. (2009). Not all survey effort is equal: Reduction of nonresponse bias and nonresponse error. Public Opinion Quarterly, 73(4), 785806. doi:10.1093/poq/nfp037.

Sakshaug, J. W., Couper, M. P., Ofstedal, M. B., \& Weir, D. R. (2012). Linking survey and administrative records: Mechanisms of consent. Sociological Methods \& Research, 41(4), 535 569. doi: $10.1177 / 0049124112460381$.

Schräpler, J.-P. (2001). Respondent behaviour in panel studies. A case study of the German SocioEconomic Panel (GSOEP). DIW-Discussion Paper 244. Berlin: DIW.

Schwerdt, G. (2011). Labor turnover before plant closure: "Leaving the sinking ship" vs. "Captain throwing ballast overboard". Labour Economics, 18(1), 93-101. doi:10.1016/j.labeco.2010.08.003.

Schwerdt, G., Ichino, A., Ruf, O., Winter-Ebmer, R., \& Zweimüller, J. (2010). Does the color of the collar matter? Employment and earnings after plant closure. Economics Letters, 137-140. doi:10.1016/j.econlet.2010.04.014

Stoop, I. (2005). The hunt for the last respondent: Nonresponse in sample survey. Hague: Sociall en Cultureel Planbu.

Sweet, S., \& Moen, P. (2011). Dual earners preparing for job loss: Agency, linked lives, and resilience. Work and Occupations, 39(1), 35-70. Retrieved from http://wox.sagepub.com/cgi/ doi/10.1177/0730888411415601.

Vannieuwenhuyze, J., \& Loosveldt, G. (2013). Evaluating relative mode effects in mixed-mode surveys: Three methods to disentangle selection and measurement effect. Sociological Methods and Research, 42(1), 82-104. 
Voorpostel, M. (2010). Attrition patterns in the Swiss household panel by demographic characteristics and social involvement. Swiss Journal of Sociology, 36(2), 359-377.

Western, B., \& Jackman, S. (1994). Bayesian inference for comparative research. The American Political Science Review, 88(2), 412-423.

Wyss, S. (2009). Stellenverlust und Lohneinbusse durch die Globalisierung? University of Basel: Eine Fallstudie. WWZ Studie 05/09 (B-100). 